\title{
Climate Change Impact on the Hydrology of a Typical Watershed in the Tianshan Mountains
}

\author{
Gonghuan Fang, ${ }^{1,2,3}$ Jing Yang, ${ }^{1,4}$ Yaning Chen, ${ }^{1}$ Shuhua Zhang, ${ }^{1,2}$ Haijun Deng, ${ }^{1,2}$ \\ Haimeng Liu, ${ }^{2,5}$ and Philippe De Maeyer ${ }^{3}$ \\ ${ }^{1}$ State Key Laboratory of Desert and Oasis Ecology, Xinjiang Institute of Ecology and Geography, Chinese Academy of Sciences, \\ Urumqi 830011, China \\ ${ }^{2}$ University of Chinese Academy of Sciences, Beijing 100049, China \\ ${ }^{3}$ Department of Geography, Ghent University, 9000 Ghent, Belgium \\ ${ }^{4}$ National Institute of Water and Atmospheric Research, Christchurch 8011, New Zealand \\ ${ }^{5}$ Institute of Geographic Sciences and Natural Resources Research, Chinese Academy of Sciences, Beijing 100101, China
}

Correspondence should be addressed to Jing Yang; yangjing@ms.xjb.ac.cn

Received 28 November 2014; Revised 26 March 2015; Accepted 15 April 2015

Academic Editor: Ming Pan

Copyright (c) 2015 Gonghuan Fang et al. This is an open access article distributed under the Creative Commons Attribution License, which permits unrestricted use, distribution, and reproduction in any medium, provided the original work is properly cited.

\begin{abstract}
To study the impact of future climatic changes on hydrology in the Kaidu River Basin in the Tianshan Mountains, two sets of future climatic data were used to force a well-calibrated hydrologic model: one is bias-corrected regional climate model (RCM) outputs for RCP4.5 and RCP8.5 future emission scenarios, and the other is simple climate change (SCC) with absolute temperature change of $-1 \sim 6^{\circ} \mathrm{C}$ and relative precipitation change of $-20 \% \sim 60 \%$. Results show the following: (1) temperature is likely to increase by $2.2^{\circ} \mathrm{C}$ and $4.6^{\circ} \mathrm{C}$ by the end of the 21 st century under RCP 4.5 and RCP 8.5 , respectively, while precipitation will increase by $2 \% \sim 24 \%$, with a significant rise in the dry season and small change in the wet season; (2) flow will change by $-1 \% \sim 20 \%$, while evapotranspiration will increase by $2 \% \sim 24 \%$; (3) flow increases almost linearly with precipitation, while its response to temperature depends on the magnitude of temperature change and flow decrease is significant when temperature increase is greater than $2^{\circ} \mathrm{C}$; (4) similar results were obtained for simulations with RCM outputs and with SCC for mild climate change conditions, while results were significantly different for intense climate change conditions.
\end{abstract}

\section{Introduction}

The Tianshan Mountains, regarded as the "water tower of Central Asia" [1], are located in the innermost center of the Eurasian continent. The long distance to the surrounding oceans causes a dry climate, especially for the surrounding basins. Rivers starting in the mountainous regions provide agricultural and domestic water for the surrounding basins and oases. With their distinctive topographic and landscape features, the Tianshan Mountains show a unique energy balance and hydrological cycle and are expected to be sensitive to climate change $[2,3]$.

Many reports show a widespread climatic and hydrologic change in the Tianshan Mountains during the past few decades [4]. For example, temperature demonstrated a significant rising trend (significant level is smaller than 0.001) at a rate of $0.33 \sim 0.34^{\circ} \mathrm{C} /$ decade during 1960 2010, which is higher than China $\left(0.25^{\circ} \mathrm{C} /\right.$ decade $)$ and the entire globe $\left(0.13^{\circ} \mathrm{C} /\right.$ decade $)[5,6]$; precipitation increased substantially in most regions especially for the middle and high latitudes; glacier area decreased by $11.5 \%$ and the thickness of snowpack has also decreased $[5,7]$. Pan evaporation and wind speed have also changed [3]. The annual runoff increased as well, for example, for the Urumqi River, the Kaidu River, and the Aksu River [8, 9].

Future changes in the streamflow and watershed hydrology have become increasingly important to water resource management in the Tianshan Mountains. However, only a limited number of studies currently focus on impact of future climate change on hydrology; for example, Sorg et al. [1] indicated that the total runoff is likely to remain stable or even increase slightly in the near future but it will decrease 
at the end of the 21st century for Central Asia. There are also researches demonstrating that the annual runoff will decrease to some extent in the first half of the 21st century $[2,10]$. Previous studies seldom address implications of climate change on the hydrological cycle and hydrological components (e.g., ET, surface flow, and groundwater). To complement these studies, this paper aims at understanding the future hydrological system and assessing the responses of the hydrologic system to climate change.

In the present study, two sets of climatic data, that is, RCM outputs and SCC data, are used to force SWAT [11] and are applied to the Kaidu River Basin, a typical watershed on the south slope of the Tianshan Mountains, to assess future changes of the hydrologic cycle and the hydrological effects of changes in climate variables. Questions that are addressed include the followings. (1) How will the future climate and hydrology change in this region? (2) What is the effect of climate change on the hydrologic cycling? (3) What is the difference between simulations with RCM outputs and SCC? Understanding these issues will enable assessing the future hydrological change and its unique hydrometeorological processes better. The remaining is constructed as follows: Section 2 introduces the study area and data; Section 3 describes the hydrological model, bias correction methods, and analysis procedures; Section 4 provides the results and discussion, followed by conclusions in Section 5 .

\section{Study Area and Data}

The Kaidu River Basin, with a drainage area of $18,634 \mathrm{~km}^{2}$ above the Dashankou hydrological station, is considered to be a very typical watershed in the Tianshan Mountains (Figure 1). Its altitude ranges from $1,342 \mathrm{~m}$ to $4,796 \mathrm{~m}$ above sea level (asl) with an average elevation of $2,995 \mathrm{~m}$. The climate here is temperate continental with alpine climate characteristics and obvious seasonal variation. This river provides water resources for agricultural activity and the ecological environment of the oasis, with an area of over $70,000 \mathrm{~km}^{2}$ and a population of over 1.15 million, which is mainly stressed by water scarcity [12]. Therefore, projecting the impact of future climate change on water resources is urgent for the sustainable development of this region and it also provides information on the implications of climate change on the water tower in Central Asia.

The daily observed meteorological data (including precipitation, maximum/minimum temperature, wind speed, and relative humidity of two meteorological stations Bayanbulak and Baluntai) from 1970 to 2005 are from the China Meteorological Data Sharing Service System (http://www .cma.gov.cn/2011qxfw/2011qsjgx/). The annual mean temperature at the Bayanbulak meteorological station amounts to $-4.1^{\circ} \mathrm{C}$ and the mean annual precipitation is $278 \mathrm{~mm}$ (Figure 1). Generally, precipitation falls as rain from May to September each year and as snow from October to April.

The observed streamflow data at the Dashankou hydrologic station are from the Xinjiang Tarim River Basin Management Bureau. The average flow at the Dashankou hydrological station amounts to approximately $120 \mathrm{~m}^{3} / \mathrm{s}$ (equivalent to $202 \mathrm{~mm}$ runoff/year), ranging from $15 \mathrm{~m}^{3} / \mathrm{s}$ to $973 \mathrm{~m}^{3} / \mathrm{s}$.

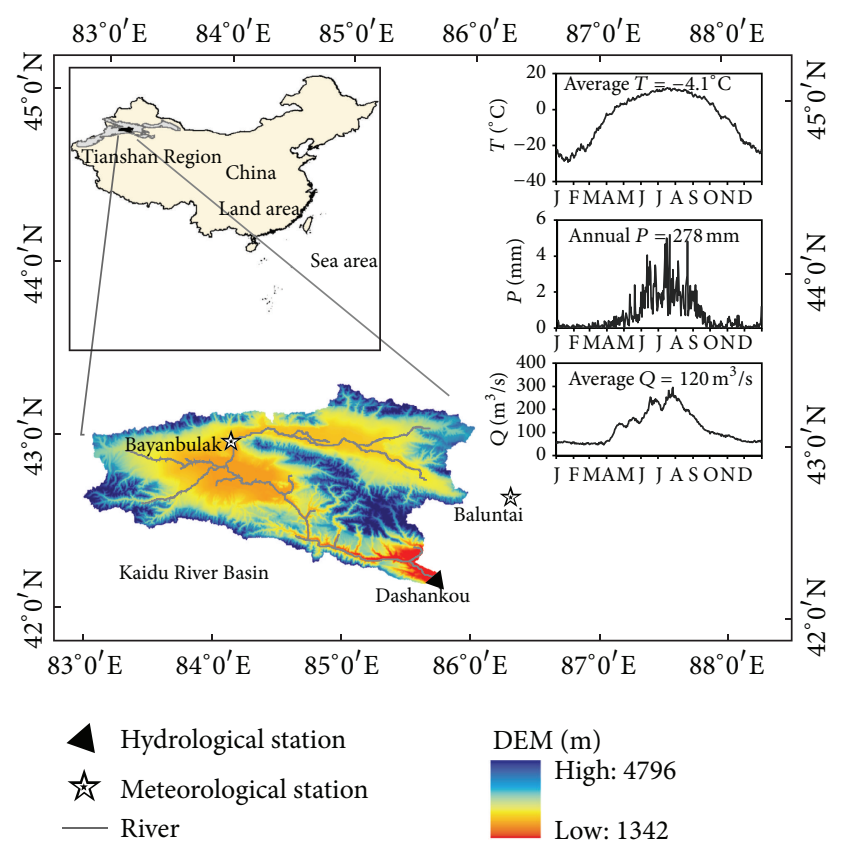

FIGURE 1: Location (top left), topography, and hydrometeorologic stations (bottom) of the Kaidu River Basin and the daily average temperature $(T)$ and precipitation $(P)$ at the Bayanbulak station and streamflow $(Q)$ at the Dashankou station (top right).

\section{Methodology}

3.1. Regional Climate Model and RCP Scenarios. The outputs of a regional climate model (RegCM4.0) [13] forced by a global climate model (Beijing Climate Center Climate System Model, BCC_CSM1.1) [14, 15] at a horizontal resolution of $50 \mathrm{~km}$ are used as future climate data. Firstly, the RCM model was validated with the observational data set over China for the period from 1976 to 2005 and then it was used to predict the future climate change under the new emission scenarios of the Representative Concentration Pathways, RCP4.5 (lower emission scenario) and RCP8.5 (higher emission scenario). RCP4.5 is a stabilization scenario with the total radiative forcing rising until 2070 and then remaining at a stable centration of $4.5 \mathrm{~W} / \mathrm{m}^{2}$. In contrast, RCP8.5 is a continuously rising radiative forcing pathway (at a target of $8.5 \mathrm{~W} / \mathrm{m}^{2}$ in 2100) with a further enhanced residual circulation and significant $\mathrm{CH}_{4}$ increases $[16,17]$. The RCM validation shows reasonable simulations of temperature and precipitation were obtained over China and, compared to the BCC_CSM1.1 model, marked improvement of the RCM was achieved in reproducing present day precipitation and temperature (for more details refer to [18]).

3.2. Bias Correction Methods. Five precipitation and three temperature correction methods were selected to bias-correct the raw RCM outputs. Precipitation correction methods include linear scaling, local intensity scaling, power transformation, distribution mapping, and quantile mapping. Temperature correction methods include linear scaling, variance scaling, and distribution mapping. They are combined into 
15 schemes to evaluate their performances in simulating streamflow. It turns out that the precipitation correction methods have more significant influence than the temperature correction methods on streamflow simulation, and the power transformation and quantile mapping perform best in terms of frequency based statistics. Thereafter, the quantile mapping method (for precipitation) and the distribution mapping (for temperature) are selected to correct the raw RCM outputs for the future period (for more details see [19]).

\subsection{Hydrologic Model and Uncertainty Analysis Method.} SWAT has been extensively used for the comprehensive modeling of the impact of management practices and climate change. SWAT simulates the hydrologic and sedimentary processes, plant growth, river routing, and in-stream water quality process, among which the surface runoff is calculated from daily rainfall and snowmelt with a modified Soil Conservation Service (SCS) curve number method [20]; water routing is simulated using variable storage or the Muskingum river routing method [11].

The SWAT model input includes the digital elevation model (DEM), soil textural and physicochemical properties, and land use data. The meteorological variables including daily precipitation, max./min. temperature, relative humidity, solar radiation, and wind speed were used to force the SWAT model. SWAT uses elevation bands to represent the topographic effects on precipitation and temperature. Within each elevation band, the precipitation and temperature are estimated based on their lapse rates. For more details, refer to the SWAT manual (http://www.brc.tamus.edu/).

The SWAT model (forced by the observed meteorological data) was calibrated against the observed streamflow. The calibration period is from 1986 to 1989 and the validation period from 1990 to 2005 [21]. The calibrated optimal parameters are then kept fixed in the following simulations. The evaluation indices for the hydrological model include NS, PBIAS, and the determination coefficient $R^{2}$. Consider

$$
\begin{aligned}
\mathrm{NS} & =1-\frac{\sum_{i=1}^{n}\left(Y_{i}^{\mathrm{obs}}-Y_{i}^{\mathrm{sim}}\right)^{2}}{\sum_{i=1}^{n}\left(Y_{i}^{\mathrm{obs}}-Y^{\mathrm{mean}}\right)^{2}}, \\
\text { PBIAS } & =\frac{\sum_{i=1}^{n}\left(Y_{i}^{\mathrm{obs}}-Y_{i}^{\mathrm{sim}}\right)}{\sum_{i=1}^{n}\left(Y_{i}^{\mathrm{obs}}\right)},
\end{aligned}
$$

where $Y_{i}^{\text {obs }}$ and $Y_{i}^{\text {sim }}$ are the $i$ th observed and simulated flows, $Y^{\text {mean }}$ is the mean of the observed data, and $n$ is the number of observations. Normally NS $>0.50, \mid$ PBIAS $\mid<25 \%$, and $R^{2}>$ 0.6 are taken as the criteria for satisfactory modeling of the river discharge and the model performance can be evaluated as excellent if NS $>0.75$ and $\mid$ PBIAS $\mid<10 \%$ [22].

GLUE (generalized likelihood uncertainty estimation) [23] is an uncertainty analysis technique, in which the parameter uncertainty accounts for all sources of uncertainty, such as input uncertainty, structure uncertainty, parameter uncertainty, and response uncertainty [24]. In GLUE, the parameter uncertainty is described as a set of discrete "behavioral" parameter sets with corresponding "likelihood weights."
The procedure of a GLUE analysis consists of three steps. Firstly, after the definition of the "generalized likelihood measure," $L(\theta)$, a large number of parameter sets are randomly sampled from the prior distribution and each parameter set is assessed as either "behavioral" or "nonbehavioral" by comparing its value of $L(\theta)$ to the threshold value. Secondly, each behavioral parameter set is given a "likelihood weight" and we gave them equal weights in this study. Finally, prediction uncertainty is represented by $5 \%$ and $95 \%$ quantiles of the cumulative distribution of the behavioral parameter sets.

Two indices are used to quantify the quality of the uncertainty performance. Those indices are the percentage of measurements bracketed by the $95 \%$ prediction uncertainty band ( $P$-factor) and width of band ( $R$-factor, calculated by the average width of the band divided by the standard deviation of the corresponding measured variable).

3.4. SCC Data Description and Analysis Procedures. In the following section, temperature and precipitation are denoted as $T$ and $P$ and the absolute and relative changes are represented by $\Delta$ and $\delta$. For example, $\Delta T$ refers to an absolute temperature change and $\delta P$ a relative precipitation change. The hydrological processes analyzed in this study include streamflow, surface runoff, subsurface runoff, and evapotranspiration, which are denoted as $Q, R_{s}, R_{g}$, and ET, and their relative changes are described as $\delta Q, \delta R_{s}, \delta R_{g}$, and $\delta \mathrm{ET}$, respectively.

The SCC was constructed to represent a wide range of changes in climatic variables and how these changes might translate in streamflow and other hydrological components and also to analyze the differences between simulations with RCM outputs and SCC. For SCC, perturbations of the corrected RCM simulated $P$ and $T$ from 1986 2005 (control period) are set; that is, for $T$, an additive change $(\Delta)$ is used: $\Delta T=-1,0,1,2,3,4,5$, and $6^{\circ} \mathrm{C}$. For $P$, a relative change $(\delta)$ is used: $\delta P=-20 \%,-10 \%, 0,10 \%, 20 \%, 30 \%$, $40 \%, 50 \%$, and $60 \%$. They are put into 81 SCC scenarios, with $\Delta T=0$ and $\delta P=0 \%$ being the climate for control period.

By investigating the transient evolution of climate change in the corrected RCM outputs on decadal scales, five periods (each spanning 20 years) are defined: 1986 2005 (control period) and 2020 2039, 2040 2059, 2060 2079, and 2080 2099. Due to the intra-annual characteristics of the hydrometeorology in the Kaidu River Basin (Figure 1), the wet season (from April to September) and dry season (from October to March next year) are defined based on the intra-annual distribution of $P$ and $Q$; for example, $P$ and $Q$ in the wet season account for $88 \%$ and $73 \%$ of their annual amounts. The climatic and hydrological changes are classified into three categories, that is, a significant change, small change, and insignificant change, to clearly demonstrate the changing magnitude according to the values of relative change for precipitation and hydrological components and absolute change of temperature. These categories are presented in Table 1 . 
TABLE 1: Classification of magnitude for climatic and hydrological changes. $\delta$ and $\Delta$ represent relative change and absolute change.

\begin{tabular}{lcc}
\hline & $\begin{array}{c}\text { Precipitation \& } \\
\text { hydrological } \\
\text { components }(\%)\end{array}$ & $\begin{array}{c}\text { Temperature } \\
\left({ }^{\circ} \mathrm{C}\right)\end{array}$ \\
\hline $\begin{array}{l}\text { Significant } \\
\text { change }\end{array}$ & $|\delta| \geq 20$ & $|\Delta| \geq 2$ \\
$\begin{array}{l}\text { Small change } \\
\begin{array}{l}\text { Insignificant } \\
\text { change }\end{array}\end{array}$ & $10 \leq|\delta|<20$ & $1 \leq|\Delta|<2$ \\
\hline
\end{tabular}

\section{Results and Discussion}

4.1. Validation of the Hydrological Model and the Bias Correction Methods. Performance of the hydrological model forced by observed meteorological data and the $95 \%$ prediction uncertainty bands are shown in Figure 2. The simulated streamflow agrees quite well with the observation for both calibration period (1986 1989) and validation period (1990 2002). For the uncertainty analysis, NS is used as $L(\theta)$ and 0.70 as threshold value with 10,000 initial parameter sets; 288 sets were selected as behavioral points. The results show that most of the observations are bracketed by the $95 \%$ prediction uncertainty band ( $P$-factor being $87 \%$ and $80 \%$ for calibration and validation periods and $R$-factor being 1.18 and 1.19 , resp.). The lower $P$-factor for the validation period can be partly attributed to operation of hydropower station since 1991 (Figure 2) which leads to great fluctuation in winter streamflow. Statistics of model efficiency (Table 2) indicate excellent performances for both calibration and validation periods, with "NS"s and " $R$ "s over 0.80 , which is highly acceptable according to Moriasi et al. [22]. Concerning the monthly streamflow, the "NS" is 0.89 during 1986 2005 and it indicates that the SWAT model captured the natural monthly streamflow variability adequately.

The performances of bias-corrected RCM outputs (compared to observed meteorological data) are listed in Table 2. The "NS"s are -0.57 (0.57) and 0.77 (0.95) for daily (monthly) precipitation and temperature for 1990 2005, respectively. And the statistics of the streamflow simulated with the biascorrected RCM outputs shows acceptable results with "NS"s equal to 0.46 and 0.62 and PBIAS within $10 \%$ for daily and monthly streamflows.

\subsection{RCM Projected Hydrometeorologic Changes}

4.2.1. Changes in Temperature and Precipitation. Temperature is highly likely to increase in the future, with a basin warming of $1.0 \sim 2.2^{\circ} \mathrm{C}$ and $1.6 \sim 4.6^{\circ} \mathrm{C}$ under RCP4.5 and RCP8.5 in the 21st century (Table 3). Temperature increases continuously under both scenarios but the magnitude is larger under RCP8.5 (Figure 3).

Precipitation shows an overall increasing trend in the 21 st century with an annual increase of $2 \% \sim 16 \%$ and $7 \%$ $24 \%$ under RCP4.5 and RCP8.5, which confirms the previous arguments of Sorg et al. [1]. However, precipitation change varies substantially among seasons (Figure 3). Normally,

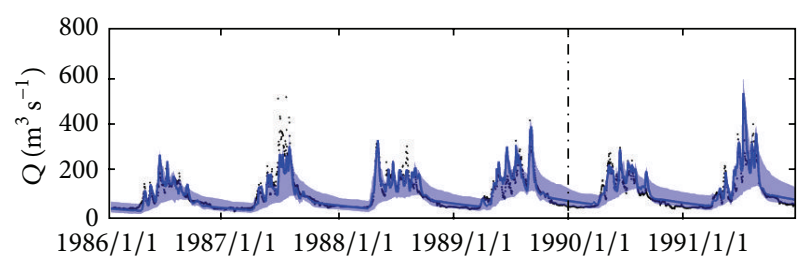

(a)

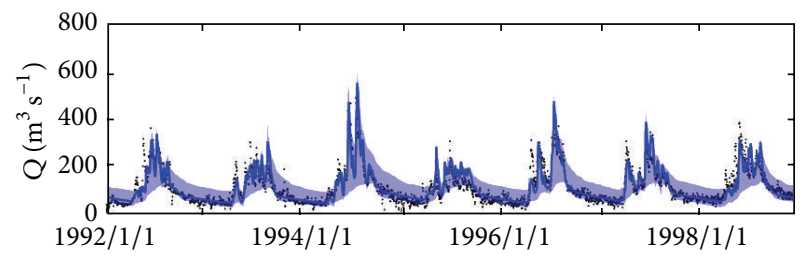

(b)

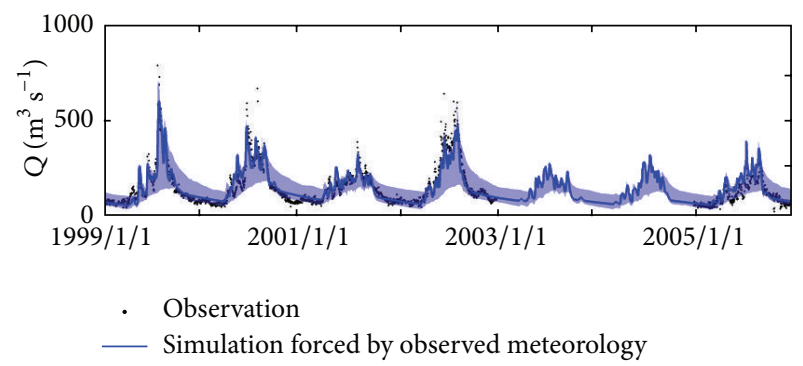

(c)

Figure 2: Time series of daily observed streamflows (dots) and simulated streamflows forced by observed meteorological data (blue line) for calibration period (1986-1989) and validation period (19902005 ) with $95 \%$ prediction uncertainty bands (blue shaded area).

a small increase in the wet season $(-2 \% \sim 16 \%)$ and a significant increase during dry season $(18 \% \sim 78 \%)$ are projected. Note that the relative increase (not the absolute increment) of precipitation for the dry season is much bigger than for the wet season, which is in line with the climate changes in other regions, for example, the semiarid Colorado River Basin [25] and the wet Ganges-Brahmaputra-Meghna basin [26].

4.2.2. Changes in the Hydrological Cycle. The changes in precipitation and temperature cause changes in potential streamflow. The average annual streamflow rises by $-1 \% \sim$ $18 \%$ and $4 \sim 20 \%$ under the RCP4.5 and RCP8.5 in the 21st century, based on the average annual streamflow of $194 \mathrm{~mm}$ for the control period (1986 2005) (Table 3). Note that the streamflow stopped increasing in 2080 2099 (end of 21st century) under RCP8.5 despite the rise in precipitation, which confirms the finding of Sorg et al. [1] and may aggravate water scarcity in this region.

Figure 3 also shows the projected changes in surface runoff $\left(R_{s}\right)$, subsurface runoff $\left(R_{g}\right)$, and evapotranspiration (ET) under RCP4.5 and RCP8.5. Overall, changes of hydrologic components are bigger for RCP8.5 than for RCP4.5. The annual change of $R_{s}$ is insignificant $(<5 \%)$ but with obvious seasonal variability; for example, changes of $R_{s}$ range from $-22 \%$ to $2 \%$ for the wet season and in $4 \% \sim 78 \%$ for the dry 

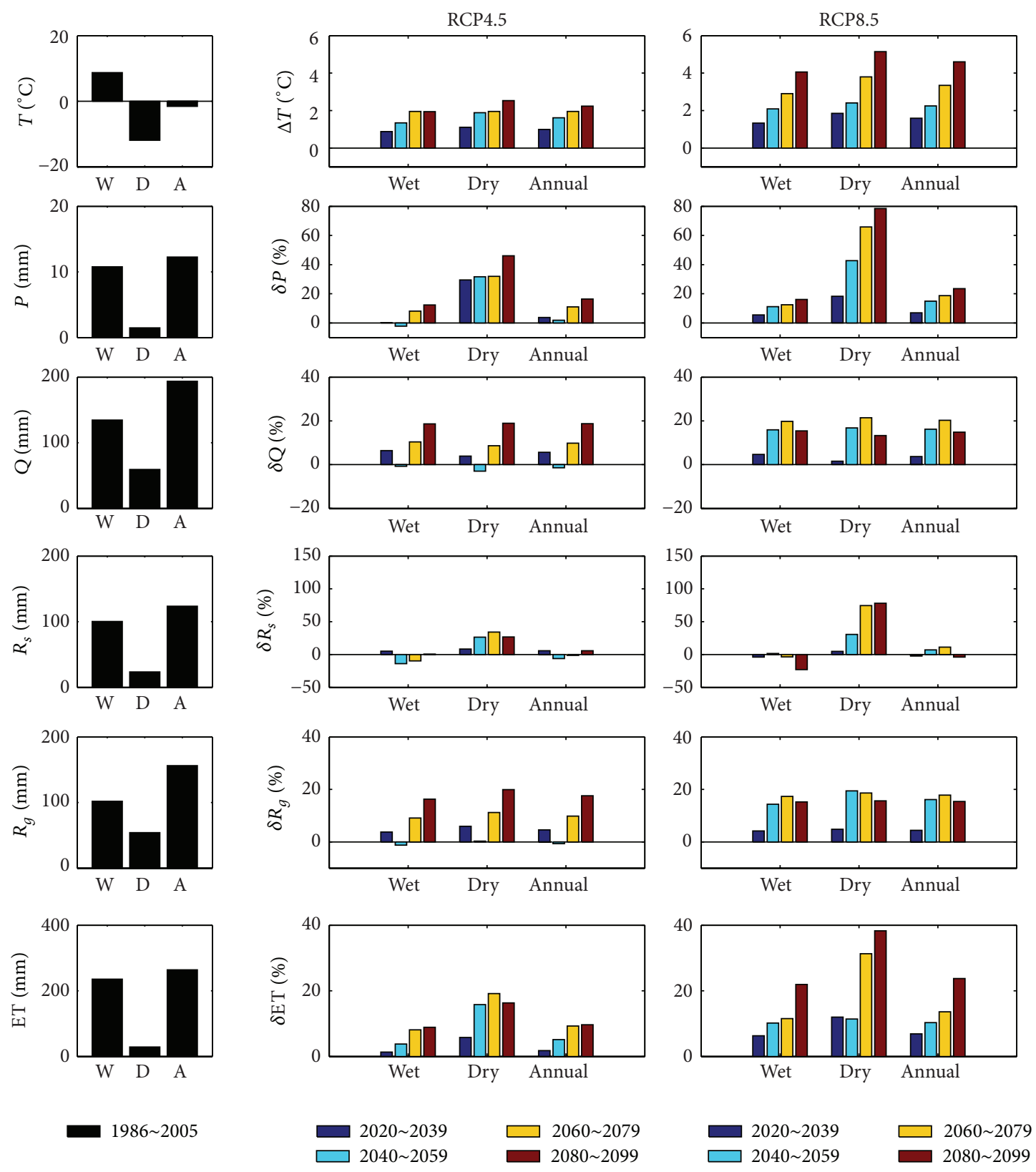

FIGURE 3: Summary of future climate inputs $(P$ and $T)$ and simulated hydrologic components $\left(Q, R_{s}, R_{g}\right.$, and ET) under RCP4.5 and RCP8.5, compared to their values in the control period (1986 2005). All these hydrometeorologic factors are presented in terms of wet season, dry season, and annual values.

season under RCP8.5. The annual $R_{g}$ changes by $-0.7 \% \sim 17 \%$ and $4 \% \sim 18 \%$ for RCP4.5 and RCP8.5, which is consistent with the changes of $Q$. ET increases continuously in the 21 st century with average increases of $2 \% \sim 10 \%$ and $7 \% \sim 24 \%$ under RCP4.5 and RCP8.5.

4.3. Response of Hydrological Cycle to Climate Change. The response of the hydrological cycle to climate change is estimated by running the hydrological model forced by SCC. The responses of $Q, R_{s}, R_{g}$, and ET to climate change are demonstrated with response surfaces in Figure 4. $Q$ is positively related to $P$ and negatively related to $T$. The relationship of $\delta Q$ and $\delta P$ is almost linear with the streamflow elasticity $(\delta Q / \delta P)$ being about 1.0 when $\Delta T<2^{\circ} \mathrm{C}$; that is, a $1 \%$ change in the mean annual precipitation results in a $1 \%$ change in the mean annual streamflow. $\delta Q / \delta P$ is lower than that for other arid regions, for example, $2.0 \sim 3.5$ for Australia [27]. The possible reasons are mentioned as follows: (1) the Kaidu River Basin, located in the south slope of the Tianshan Mountains with a high average altitude $(2,995 \mathrm{~m})$, is characterized by a cold climate (average annual temperature is $-4.1^{\circ} \mathrm{C}$ for the Bayanbulak station) and accordingly there is a low amount of energy available for ET, which results in a relatively high runoff coefficient $(Q / P=0.51)$ and consequently a low 
TABLE 2: Statistics of bias-corrected RCM outputs and SWAT simulated streamflows forced by the observed climate variables and biascorrected RCM outputs.

\begin{tabular}{lcc}
\hline Statistics & NS & PBIAS \\
\hline "RCM simulated precipitation with bias correction"a & $-6.80 \%$ \\
Validation period 1990 2005 (daily) & -0.57 & $-6.80 \%$ \\
Validation period 1990 2005 (monthly) & 0.57 & 0.00 \\
"RCM simulated maximum temperature with bias correction" & & 0.60 \\
Validation period 1990 2005 (daily) & 0.77 & $0.80 \%$ \\
$\quad$ Validation period 1990 2005 (monthly) & 0.95 & $0.00 \%$ \\
"Streamflow simulated with observed meteorological data" & & $0.01 \%$ \\
Calibration period 1986 1989 (daily) & 0.80 & $2.94 \%$ \\
First validation period 1990 2002 (daily) & 0.81 & 0.80 \\
Second validation period 1986 2005 (monthly) & 0.89 & 0.81 \\
"Streamflow simulated with bias-corrected RCM outputs" & & 0.90 \\
Validation period 1990 2002 (daily) & 0.46 & $-6.98 \%$ \\
Validation period 1986 2005 (monthly) & 0.62 & $-7.85 \%$ \\
\hline
\end{tabular}

${ }^{\mathrm{a}}$ Bias correction methods used are quantile mapping for precipitation and distribution mapping for temperature [19].

b" Daily" or "monthly" in the brackets means the time step used to calculate the statistics.

TABLE 3: RCM projected precipitation change $(\delta P)$, temperature change $(\Delta T)$, and streamflow change $(\delta Q)$ for the 21 st century under RCP4.5 and RCP8.5 compared to the control period (1986 2005).

\begin{tabular}{|c|c|c|c|c|c|}
\hline & & $2020 \sim 2039$ & $2040 \sim 2059$ & $2060 \sim 2079$ & 2080 2099 \\
\hline \multirow{3}{*}{ RCP4.5 } & $\delta P(\%)$ & 4.0 & 2.0 & 11.0 & 16.0 \\
\hline & $\Delta T\left({ }^{\circ} \mathrm{C}\right)$ & 1.0 & 1.6 & 2.0 & 2.2 \\
\hline & $\delta Q(\%)$ & 6.0 & -1.0 & 10.0 & 18.0 \\
\hline \multirow{3}{*}{ RCP8.5 } & $\delta P(\%)$ & 7.0 & 15.0 & 19.0 & 24.0 \\
\hline & $\Delta T\left({ }^{\circ} \mathrm{C}\right)$ & 1.6 & 2.3 & 3.3 & 4.6 \\
\hline & $\delta Q(\%)$ & 4.0 & 16.0 & 20.0 & 15.0 \\
\hline
\end{tabular}

streamflow elasticity; (2) the streamflow is also influenced by temperature dominated snowmelt (snowfall accounts for about $17 \%$ of watershed precipitation), which reduces the dependence of streamflow on precipitation and therefore results in a low streamflow elasticity [27].

The response of $Q$ to $\Delta T$ depends on the magnitude of $\Delta T$. $Q$ decreases slightly when $0<\Delta T \leq 2.0^{\circ} \mathrm{C}$ while it decreases dramatically when $\Delta T>2.0^{\circ} \mathrm{C}$ for both wet and dry seasons. For example, when $\Delta T=2.0^{\circ} \mathrm{C}$, a $40 \%$ precipitation increase results in an average value of $Q$ being $240 \mathrm{~mm}$ (23\% increase compared to the average streamflow of $194 \mathrm{~mm}$ ) but when $\Delta T=4.0^{\circ} \mathrm{C}$, the same precipitation increase only generates an average $Q$ of $180 \mathrm{~mm}$ (about 7\% decrease) (Figure 4 ).

The responses of $R_{s}, R_{g}$, and ET to climate change are also demonstrated in Figure 4. For $R_{s}$, the responses of $R_{s}$ to $\Delta T$ are quite different for the wet and dry seasons: the higher $\Delta T$, the lower $R_{s}$ for the wet season but the higher $R_{s}$ for the dry season. Since $R_{s}$ in the dry season only accounts for $13 \%$ of the annual $R_{s}$, the response of annual $R_{s}$ is consistent with that of the wet season. For $R_{g}$, the responses of $R_{g}$ to $\Delta T$ and $\delta P$ are similar to the responses of $Q$ due to the dominant role of groundwater recharge in water yield in the Kaidu River Basin. For ET, it is mainly influenced by $\Delta T$ with temperature sensitivity $(\delta \mathrm{ET} / \Delta T)$ being $7.3 \% /{ }^{\circ} \mathrm{C}$. To verify this result, we firstly investigated basin-scale energy and water budget using the Budyko method $[28,29]$. It is shown that ET is mainly energy limited rather than water limited (average ET $/ P=$ 0.67 and $\mathrm{PET} / P=0.88)$. Secondly, the high determinate coefficient $R^{2}=0.75$ (significant level is smaller than 0.01 ) between the mean annual $T$ and ET also indicates that ET has a strong correlation with $T$. This is consistent with previous studies, which have shown that a significant variation in $\mathrm{ET}$ is expected to follow changes in air temperature [30, 31].

In addition, simulations with RCM outputs are shown in Figure 4 to analyze the differences between simulations of these two data sets. Two typical periods of RCM simulations are selected, that is, 2020 2039 under RCP4.5 and 2080 2099 under RCP8.5, to represent mild and intense climate change scenarios (shown as blue and red stars in Figure 4). It is indicated that the simulations of hydrological components with RCM outputs for 2020 2039 under RCP4.5 (mild climate change) are close to these of the nearby contour lines (simulations with SCC), which suggests that similar results of $Q, R_{s}, R_{g}$, and ET are obtained for RCM outputs and for SCC under mild climate change scenarios. However, for 2080 2099 under RCP8.5 with $\delta P=24 \%$ and $\Delta T=$ $4.6^{\circ} \mathrm{C}$, the simulated values of $Q, R_{s}, R_{g}$, and ET deviate from the simulations of SCC. There are two possible reasons: (1) changes of other meteorological inputs, that is, solar radiation, wind speed, and humidity, are slightly smaller for 

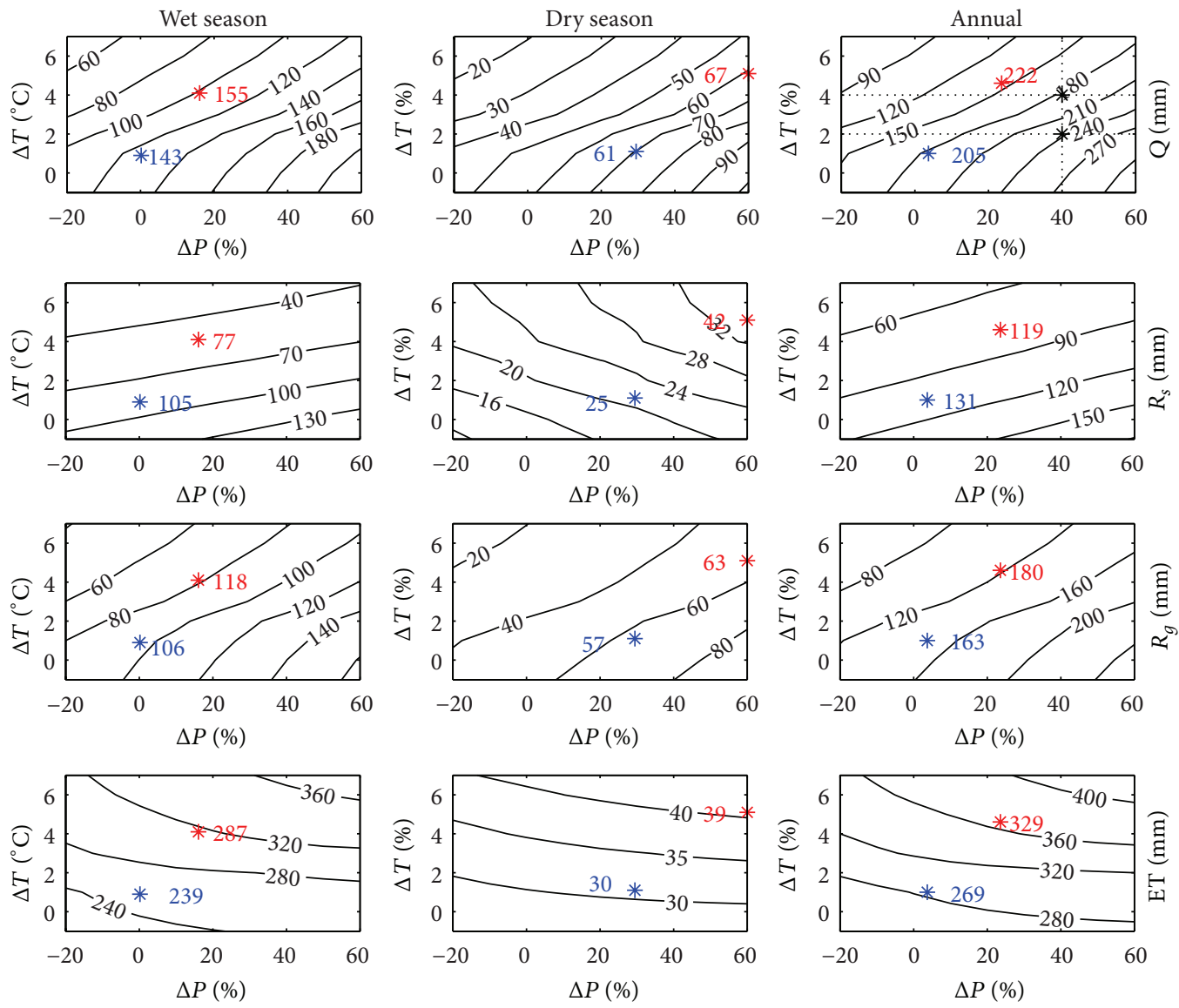

Figure 4: Response surfaces of streamflow $(Q)$, surface runoff $\left(R_{s}\right)$, subsurface runoff $\left(R_{q}\right)$, and evapotranspiration (ET) to climate change. The simulations with RCM outputs for 2020 2039 under RCP4.5 and for 2080 2099 under RCP8.5 (their corresponding meteorological changes are listed in Table 3) are indicated using blue and red stars with labels.

2020 2039 under RCP4.5 than those for 2080 2099 under RCP8.5 (-0.8\%, $2.6 \%$, and $0.9 \%$ compared to $-2.2 \%, 4.1 \%$, and 1.4\%); (2) for 2080 2099 under RCP8.5, precipitation increases by $24 \%$ with great seasonal variation, which may alter the hydrological regime; for example, precipitation increases by $139 \%$ for March, April, and May while it decreases by $-0.1 \%$ for June, July, and August. Since changes of solar radiation, wind speed, and humidity are within $\pm 5 \%$, the second reason, that is, the shift of the precipitation temporal distribution, contributes a lot to the deviation of simulations with RCM outputs from simulations with SCC.

Furthermore, the exceedance probability curves of the annual runoff in response to climate change are demonstrated in Figure 5 . The exceedance probability curves are almost parallel when $\Delta T$ ranges in $0 \sim 6^{\circ} \mathrm{C}$. However, the responses of $Q$ to $\delta P$ are not the same for each exceedance probability: high sensitivity of $Q$ with probabilities less than 0.1 and low sensitivity of $Q$ with probabilities larger than 0.9 . A comparison of the simulations with RCM outputs (four future periods under RCP4.5 and RCP8.5) and with SCC (the same changes in $T$ or $P$ with the corresponding RCM outputs) indicates that differences between simulation with RCM outputs and SCC are becoming greater as climate change gets more intense; for example, the simulation with RCM for 2080 2099 under RCP8.5 overestimates the corresponding simulations with SCC (Figure 5(h)), which collaborates the conclusion that under intense climate change scenarios the simulated hydrology with RCM deviates from that simulated with SCC.

The contributions of hydrologic components to water yield are displayed by the De Finetti diagram in Figure 6. For the control period, the averages of $R_{s}, R_{g}$, and ET are 0.22 , 0.28 , and 0.50 . For SCC, as $\Delta T$ increases from 0 to $6^{\circ} \mathrm{C}$, the contribution of ET increases rapidly from 0.49 to 0.73 and the contributions of $R_{s}$ and $R_{g}$ decrease from 0.22 to 0.11 and from 0.29 to $0.16 . \Delta T$ has a more significant influence on the proportion change than $\delta P$. As $\delta P$ changes from $-20 \%$ to $60 \%$, ET decreases from 0.71 to 0.58 and $R_{s}$ and $R_{g}$ increase from 0.13 to 0.15 and from 0.16 to 0.27 . For simulations with RCM outputs, proportions of hydrological components do not change significantly under RCP4.5, while the proportion of ET shows a significant increase under RCP8.5.

4.4. Sources of Uncertainty and Other Considerations. There are uncertainties in estimating climate change impact on hydrology. As indicated by previous studies [32], the sources 


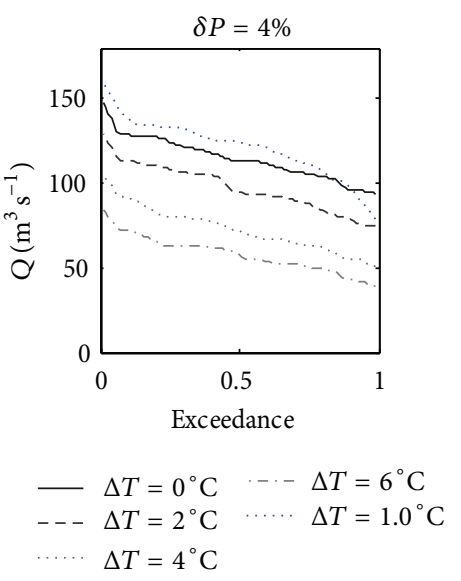

(a)

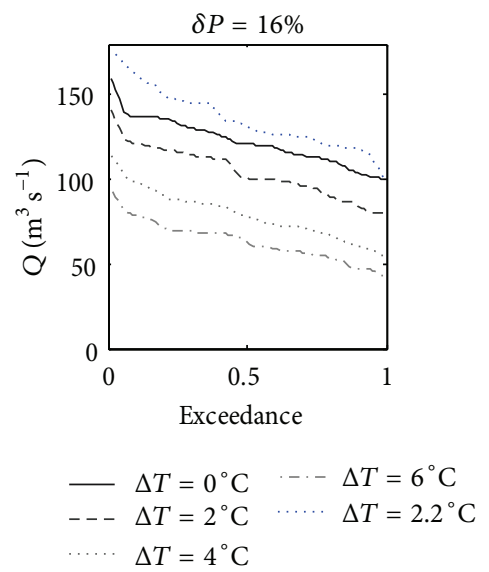

(d)

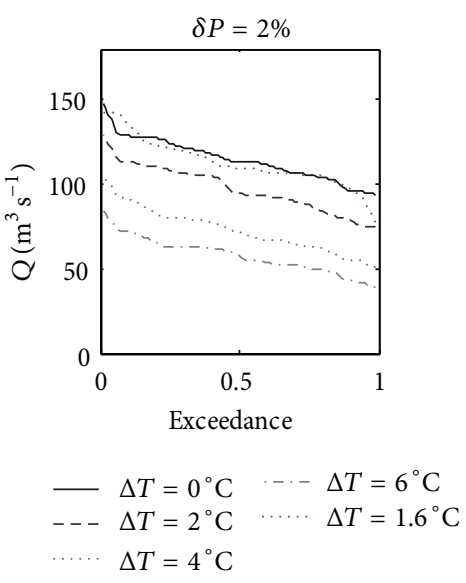

(b)

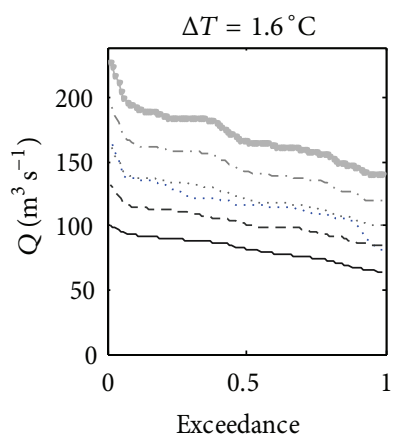
$-\delta P=20 \% \quad-\quad \delta P=40 \%$
$--\delta P=0 \% \rightarrow \delta P=60 \%$
$\delta P=20 \% \quad \cdots \cdots \quad \delta P=7 \%$

(e)

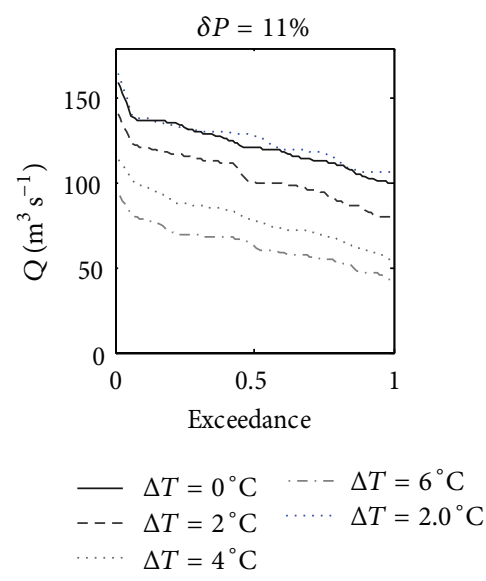

(c)

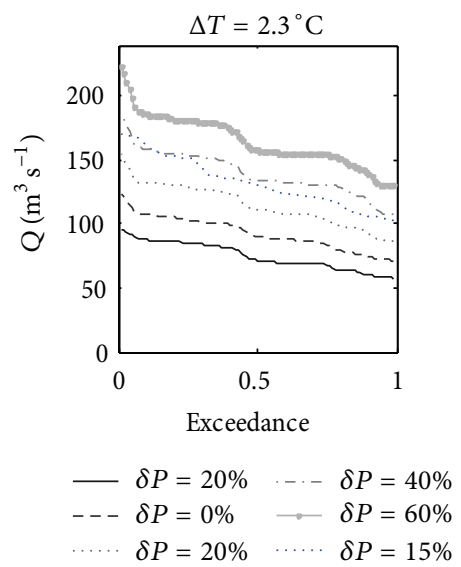

(f)

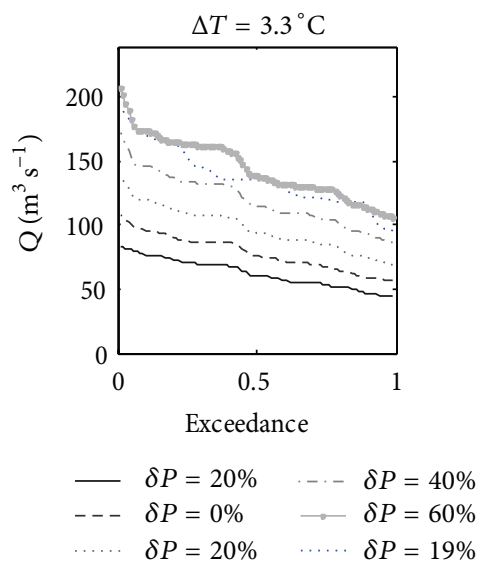

(g)

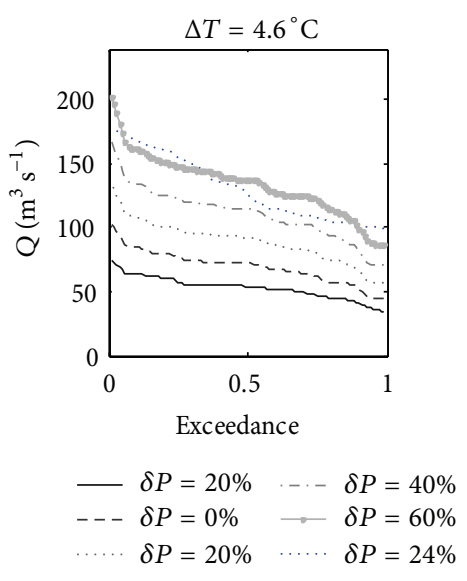

(h)

FIGURE 5: Exceedance probability curves of average annual streamflow $(Q)$ in response to temperature change and precipitation change based on SCC with each plot either with fixed precipitation change (a d) or with fixed temperature change (e h). Dotted blue line in each plot denotes exceedance probability curves of average annual streamflow for the simulation with RCM outputs given fixed $\delta P$ and $\Delta T$ as summarized in Table 3.

of uncertainty may rise from climate models, emission scenarios, downscaling, and the hydrological model.

For hydrological modeling itself, the effect of future climate in any specific catchment is difficult to project due to the possibility that the hydrological system may not be stationary with complex feedbacks [33]. For example, the same land cover and soil data were used for both control period and future climate change period, which may not well represent 


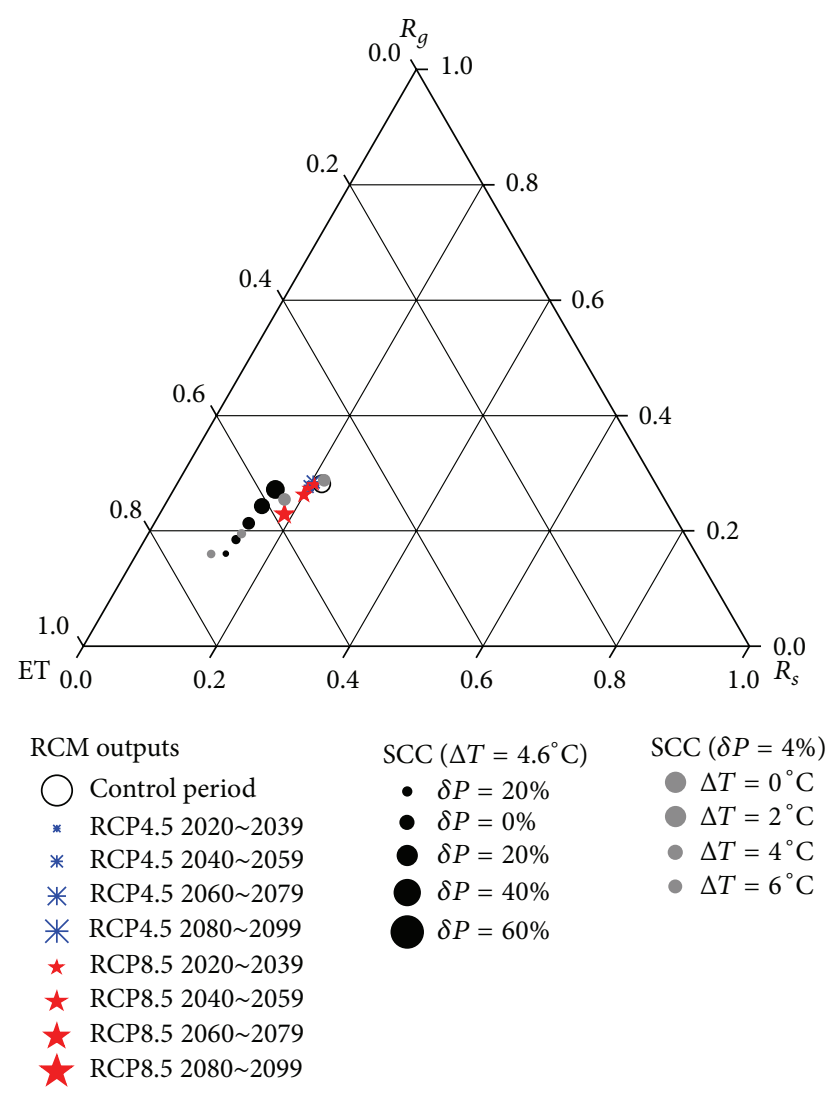

FIGURE 6: De Finetti diagram (ternary plot) of evapotranspiration (ET), surface runoff $\left(R_{s}\right)$, and subsurface runoff $\left(R_{g}\right)$ for SCC (shown as dots) and RCM outputs (shown as stars; for details of the projected changes in RCM outputs refer to Table 3 ).

the land surface under the future climate changes. Effects of land cover change on streamflows and other components of the hydrological cycle are not considered.

Though uncertainty in hydrologic modeling was quantified with the GLUE method, it only accounts for part of the total uncertainty in climate change impact studies [34]. Uncertainties associated with the climate model and downscaling were not considered here although two emission scenarios were included. Any uncertainty associated with them may cause the results to deviate from reality. However, we are dedicated to pursuing a thorough investigation of the response of the hydrological cycle to future climate change for this region and we believe this study is an important first step in achieving this goal.

\section{Conclusions}

This study assessed the implications of climate change on hydrology in a typical watershed in the Tianshan Mountains with two sets of climatic data, that is, RCM outputs and SCC, loosely coupled to a hydrological model (SWAT). Major conclusions can be summarized as follows:

(1) The hydrological model shows excellent performance with "NS"s over 0.8 for the daily streamflow for both calibration and validation periods. And the selected bias correction methods were effective in downscaling RCM outputs, with "NS"s being 0.57 and 0.95 regarding monthly precipitation and temperature.

(2) $\mathrm{T}$ increases by $1.0^{\circ} \mathrm{C} \sim 2.2^{\circ} \mathrm{C}$ and by $1.6^{\circ} \mathrm{C} \sim 4.6^{\circ} \mathrm{C}$ under RCP4.5 and RCP8.5 in the 21st century. For $P$, it shows an overall increasing trend $(2 \% \sim 24 \%)$ with significant increase for the dry season (18\% 78\%) and relatively small change for the wet season $(-2 \% \sim 16 \%)$. The projected $Q$ shows an overall increasing trend $(-1 \%$ $18 \%$ and $4 \sim 20 \%$ for RCP4.5 and RCP8.5) in the 21st century.

(3) $Q$ increases almost linearly with $P$ while the response of $Q$ to $T$ depends on the magnitude of $\Delta T$ and $Q$ decreases significantly when $\Delta T$ is greater than $2^{\circ} \mathrm{C}$.

(4) Similar responses of $Q, R_{s}, R_{g}$, and ET to $P$ and $T$ are obtained for the RCM outputs and for SCC under mild climate change scenarios. However, for intense climate change scenarios, simulations of $Q, R_{s}, R_{g}$, and ET with RCM outputs (e.g., for 2080 2099 under RCP8.5) deviate from simulations with SCC.

(5) $\Delta T$ has more significant influence on the proportion change of each hydrologic component than $\delta P$ does. As $\Delta T$ increases from 0 to $6^{\circ} \mathrm{C}$, the contribution of ET increases rapidly from 0.49 to 0.73 and $R_{s}$ and $R_{g}$ decrease by 0.11 and 0.13 . As $\delta P$ changes from $-20 \%$ to $60 \%, \mathrm{ET}, R_{s}$, and $R_{g}$ change by $-0.13,0.02$, and 0.11 as a result.

It is valuable to quantify the future responses of hydrology to climate change in the Tianshan Mountains. This study will provide useful information for water resource management and will serve as a basis for further climate change impact studies.

\section{Conflict of Interests}

The authors declare that there is no conflict of interests regarding the publication of this paper.

\section{Acknowledgments}

Research was supported by the "Thousand Youth Talents Plan" (Xinjiang Project), the National Natural Science Foundation of China (41471030), and the Foundation of State Key Laboratory of Desert and Oasis Ecology (Y371163). The authors wish to thank Professor Xuejie Gao at the National Climate Center (China) for providing the outputs of the regional climate model used in this paper.

\section{References}

[1] A. Sorg, T. Bolch, M. Stoffel, O. Solomina, and M. Beniston, "Climate change impacts on glaciers and runoff in Tien Shan (Central Asia)," Nature Climate Change, vol. 2, no. 10, pp. 725731, 2012.

[2] Z. Liu, Z. Xu, J. Huang, S. P. Charles, and G. Fu, "Impacts of climate change on hydrological processes in the headwater 
catchment of the Tarim River basin, China," Hydrological Processes, vol. 24, no. 2, pp. 196-208, 2010.

[3] Z. Li, Y. Chen, Y. Shen, Y. Liu, and S. Zhang, "Analysis of changing pan evaporation in the arid region of Northwest China," Water Resources Research, vol. 49, no. 4, pp. 2205-2212, 2013.

[4] Y. Shi, Y. Shen, E. Kang et al., "Recent and future climate change in Northwest China," Climatic Change, vol. 80, no. 3-4, pp. 379393, 2007.

[5] S. Wang, M. Zhang, Z. Li et al., "Glacier area variation and climate change in the Chinese Tianshan Mountains since 1960," Journal of Geographical Sciences, vol. 21, no. 2, pp. 263-273, 2011.

[6] B. Li, Y. Chen, and X. Shi, "Why does the temperature rise faster in the arid region of northwest China?" Journal of Geophysical Research D: Atmospheres, vol. 117, no. 16, Article ID D16115, 2012.

[7] V. B. Aizen, E. M. Aizen, J. M. Melack, and J. Dozier, "Climatic and hydrologic changes in the Tien Shan, central Asia," Journal of Climate, vol. 10, no. 6, pp. 1393-1404, 1997.

[8] B. Ye, D. Yang, K. Jiao et al., "The Urumqi River source Glacier No. 1, Tianshan, China: changes over the past 45 years," Geophysical Research Letters, vol. 32, no. 21, Article ID L21504, 2005.

[9] H. Wang, Y. Chen, W. Li, and H. Deng, "Runoff responses to climate change in arid region of northwestern China during 1960-2010," Chinese Geographical Science, vol. 23, no. 3, pp. 286300, 2013.

[10] T. Liu, P. Willems, X. L. Pan et al., "Climate change impact on water resource extremes in a headwater region of the Tarim basin in China," Hydrology and Earth System Sciences, vol. 15, no. 11, pp. 3511-3527, 2011.

[11] J. G. Arnold, R. Srinivasan, R. S. Muttiah, and J. R. Williams, "Large area hydrologic modeling and assessment part I: model development," Journal of the American Water Resources Association, vol. 34, no. 1, pp. 73-89, 1998.

[12] Y. Chen and Q. Du, Sustainable Water Use in the Bosten Lake Basin, Science Press, Beijing, China, 2013.

[13] F. Giorgi and L. O. Mearns, "Introduction to special section: regional climate modeling revisited," Journal of Geophysical Research, vol. 104, no. D6, pp. 6335-6352, 1999.

[14] T. Wu, W. Li, J. Ji et al., "Global carbon budgets simulated by the Beijing climate center climate system model for the last century," Journal of Geophysical Research D: Atmospheres, vol. 118, no. 10, pp. 4326-4347, 2013.

[15] X. Xin, T. Wu, J. Li et al., "How well does BCC_CSM1. 1 reproduce the 20th Century climate change over China?" Atmospheric and Oceanic Science Letters, vol. 6, pp. 21-26, 2013.

[16] D. P. van Vuuren, J. Edmonds, M. Kainuma et al., "The representative concentration pathways: an overview," Climatic Change, vol. 109, no. 1, pp. 5-31, 2011.

[17] H. Kawase, T. Nagashima, K. Sudo, and T. Nozawa, "Future changes in tropospheric ozone under Representative Concentration Pathways (RCPs)," Geophysical Research Letters, vol. 38, no. 5, 2011.

[18] X. Gao, M. Wang, and F. Giorgi, "Climate change over China in the 21st century as simu-lated by BCC_CSM1.1-RegCM4.0," Atmospheric and Oceanic Science Letters, vol. 6, pp. 381-386, 2013.

[19] G. H. Fang, J. Yang, Y. N. Chen, and C. Zammit, "Comparing bias correction methods in downscaling meteorological variables for hydrologic impact study in an arid area in China," Hydrology and Earth System Sciences Discussions, vol. 11, no. 11, pp. 12659-12696, 2014.
[20] Soil Conservation Service, "Urban hydrology for small watershed," Technical Release 55, U.S. Department of Agriculture, 1968.

[21] G. Fang, J. Yang, Y. Chen, C. Xu, and P. de Maeyer, "Contribution of meteorological input in calibrating a distributed hydrologic model in a watershed in the Tianshan Mountains, China," Environmental Earth Sciences, 2015.

[22] D. N. Moriasi, J. G. Arnold, M. W. van Liew, R. L. Bingner, R. D. Harmel, and T. L. Veith, "Model evaluation guidelines for systematic quantification of accuracy in watershed simulations," Transactions of the ASABE, vol. 50, no. 3, pp. 885-900, 2007.

[23] K. Beven and A. Binley, "The future of distributed models: model calibration and uncertainty prediction," Hydrological Processes, vol. 6, no. 3, pp. 279-298, 1992.

[24] J. Yang, P. Reichert, K. C. Abbaspour, J. Xia, and H. Yang, "Comparing uncertainty analysis techniques for a SWAT application to the Chaohe Basin in China," Journal of Hydrology, vol. 358, no. 1-2, pp. 1-23, 2008.

[25] N. S. Christensen and D. P. Lettenmaier, "A multimodel ensemble approach to assessment of climate change impacts on the hydrology and water resources of the Colorado River Basin," Hydrology and Earth System Sciences, vol. 11, no. 4, pp. 1417-1434, 2007.

[26] M. Masood, P. J. Yeh, N. Hanasaki, and K. Takeuchi, "Model study of the impacts of future climate change on the hydrology of Ganges-Brahmaputra-Meghna basin," Hydrology and Earth System Sciences, vol. 19, no. 2, pp. 747-770, 2015.

[27] F. H. S. Chiew, "Estimation of rainfall elasticity of streamflow in Australia," Hydrological Sciences Journal, vol. 51, no. 4, pp. 613$625,2006$.

[28] J. A. Jones, I. F. Creed, K. L. Hatcher et al., "Ecosystem processes and human influences regulate streamflow response to climate change at long-term ecological research sites," BioScience, vol. 62, no. 4, pp. 390-404, 2012.

[29] M. I. Budyko, Climate and Life, Academic Press, New York, NY, USA, 1974.

[30] K. C. Abbaspour, M. Faramarzi, S. S. Ghasemi, and H. Yang, "Assessing the impact of climate change on water resources in Iran," Water Resources Research, vol. 45, no. 10, 2009.

[31] S. G. Setegn, D. Rayner, A. M. Melesse, B. Dargahi, and R. Srinivasan, "Impact of climate change on the hydroclimatology of Lake Tana Basin, Ethiopia," Water Resources Research, vol. 47, no. 4, Article ID W04511, 2011.

[32] S. Hagemann, C. Chen, D. B. Clark et al., "Climate change impact on available water resources obtained using multiple global climate and hydrology models," Earth System Dynamics, vol. 4, no. 1, pp. 129-144, 2013.

[33] R. P. Silberstein, S. K. Aryal, J. Durrant et al., "Climate change and runoff in south-western Australia," Journal of Hydrology, vol. 475, pp. 441-455, 2012.

[34] D. G. Kingston and R. G. Taylor, "Sources of uncertainty in climate change impacts on river discharge and groundwater in a headwater catchment of the Upper Nile Basin, Uganda," Hydrology and Earth System Sciences, vol. 14, no. 7, pp. 12971308, 2010. 

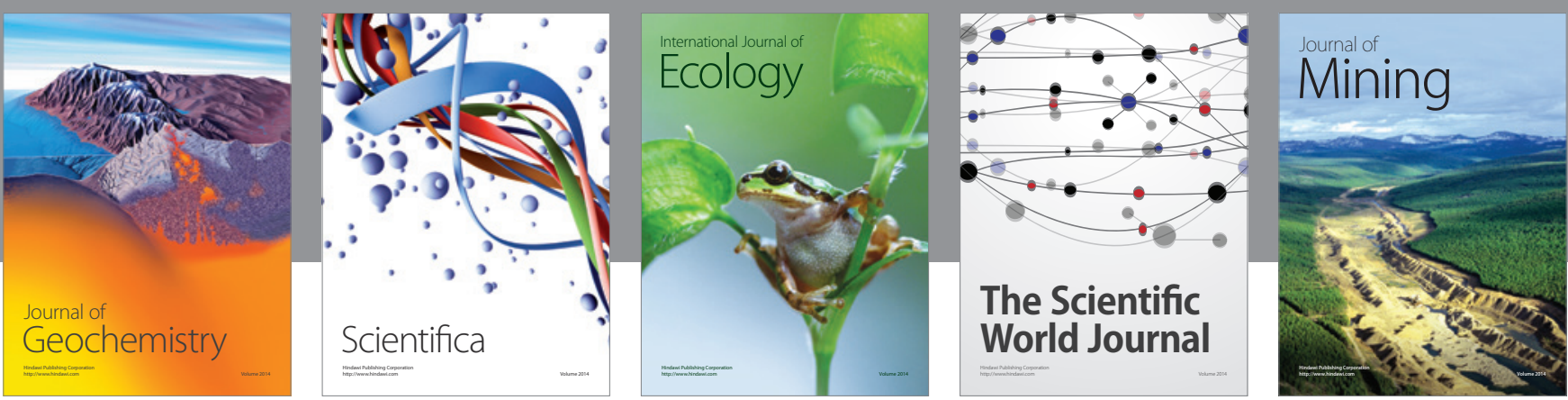

The Scientific World Journal
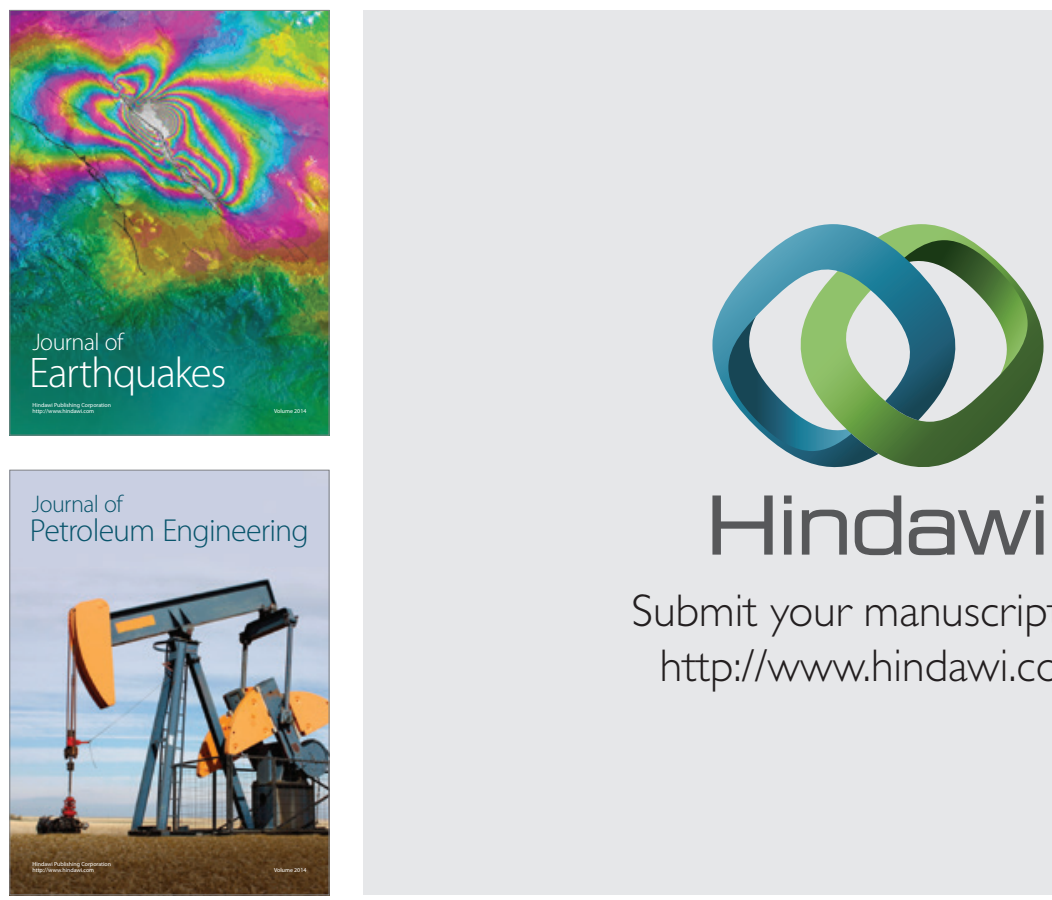

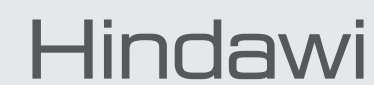

Submit your manuscripts at

http://www.hindawi.com
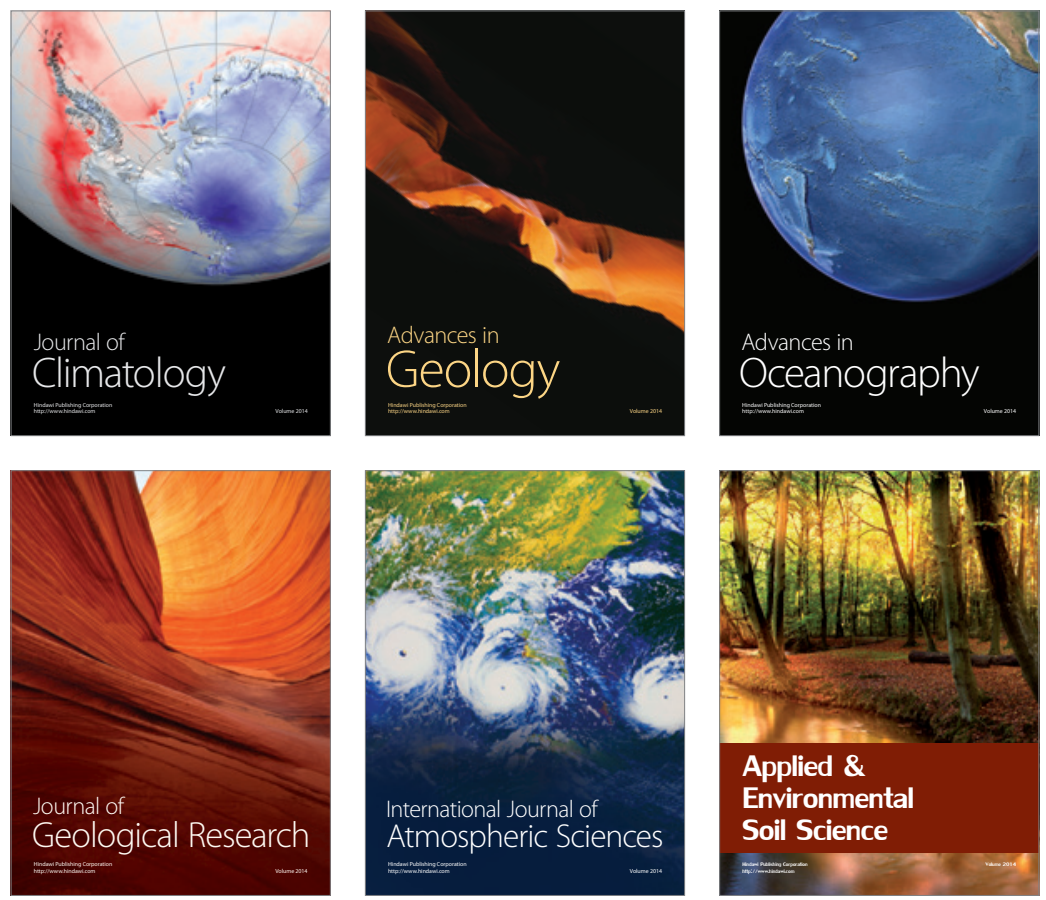
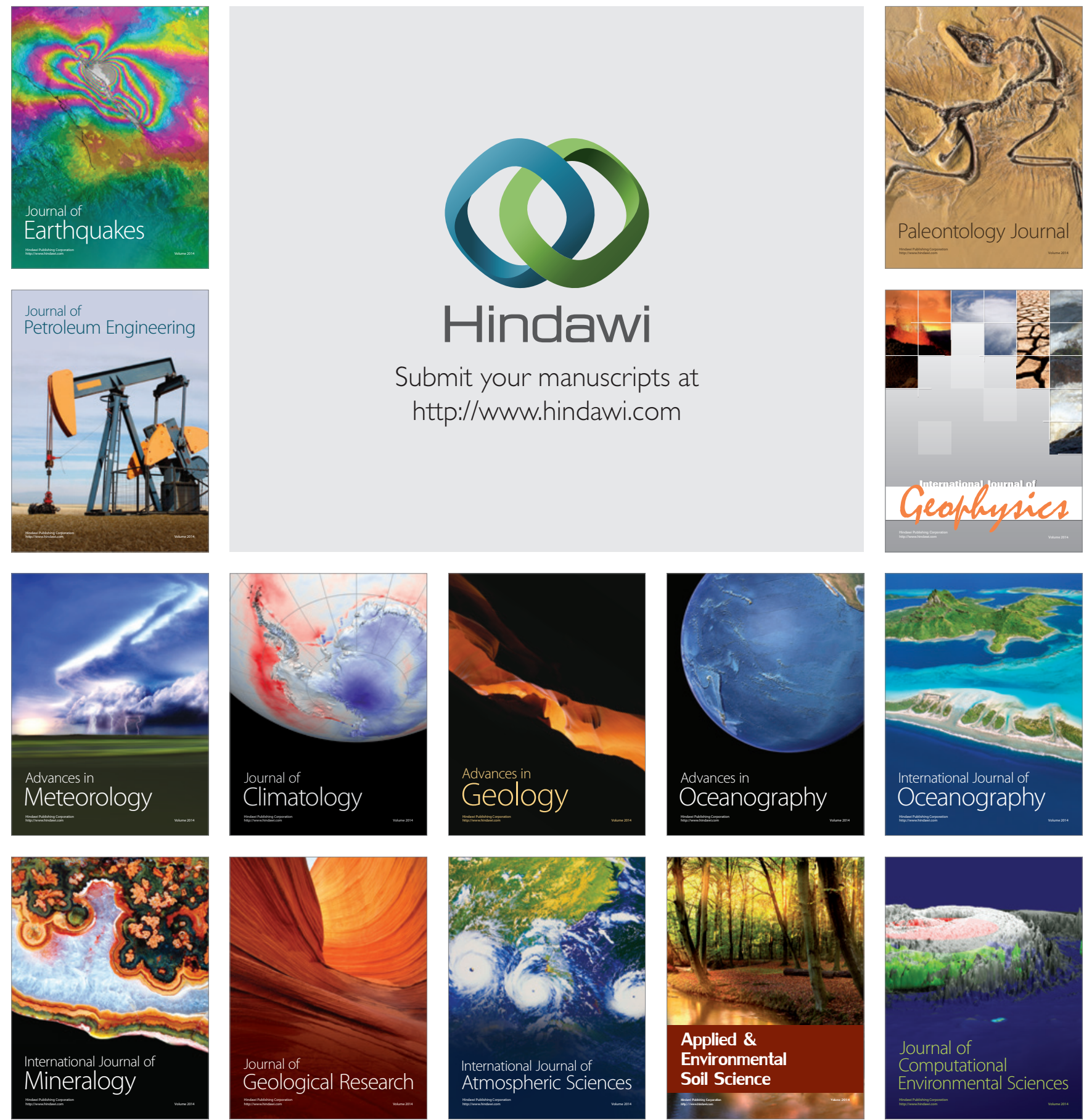